ARTICLE

https://doi.org/10.1038/s41467-019-09629-5

\title{
Distinguishing the sources of silica nanoparticles by dual isotopic fingerprinting and machine learning
}

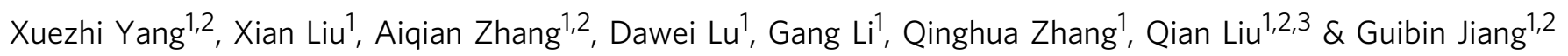

One of the key shortcomings in the field of nanotechnology risk assessment is the lack of techniques capable of source tracing of nanoparticles (NPs). Silica is the most-produced engineered nanomaterial and also widely present in the natural environment in diverse forms. Here we show that inherent isotopic fingerprints offer a feasible approach to distinguish the sources of silica nanoparticles $\left(\mathrm{SiO}_{2} \mathrm{NPs}\right)$. We find that engineered $\mathrm{SiO}_{2} \mathrm{NPs}$ have distinct $\mathrm{Si}-\mathrm{O}$ two-dimensional (2D) isotopic fingerprints from naturally occurring $\mathrm{SiO}_{2} \mathrm{NPs}$, due probably to the $\mathrm{Si}$ and $\mathrm{O}$ isotope fractionation and use of isotopically different materials during the manufacturing process of engineered $\mathrm{SiO}_{2} \mathrm{NPs}$. A machine learning model is developed to classify the engineered and natural $\mathrm{SiO}_{2} \mathrm{NPs}$ with a discrimination accuracy of $93.3 \%$. Furthermore, the $\mathrm{Si}-\mathrm{O}$ isotopic fingerprints are even able to partly identify the synthetic methods and manufacturers of engineered $\mathrm{SiO}_{2} \mathrm{NPs}$.

\footnotetext{
${ }^{1}$ State Key Laboratory of Environmental Chemistry and Ecotoxicology, Research Center for Eco-Environmental Sciences, Chinese Academy of Sciences, Beijing 100085, China. ${ }^{2}$ College of Resources and Environment, University of Chinese Academy of Sciences, Beijing 100190, China. ${ }^{3}$ Institute of Environment and Health, Jianghan University, Wuhan 430056, China. Correspondence and requests for materials should be addressed to Q.L. (email: qianliu@rcees.ac.cn) or to G.J. (email: gbjiang@rcees.ac.cn)
} 
$\mathrm{N}$ anoparticles (NPs) in the environment can occur naturally or originate from engineered nanomaterials released by human activities. Nowadays, the production and disposal amounts of engineered NPs are increasing rapidly, which raises significant health and safety concerns about the use of $\mathrm{NPs}^{1,2}$. Distinguishing the sources of NPs is of extreme importance for nano research, especially in areas of nanotechnology risk assessment, NP exposure monitoring, environmental fate studies, and nano-product analysis 3,4 . Although engineered NPs are usually produced in high purity, it is still one of the most challenging tasks in nanoanalytics to detect/distinguish them in complex natural media. In earlier works, the sources of NPs were normally identified by the means of morphology or chemical composition (e.g., multi-element analysis at single-particle levels that provided a basis for distinguishing between natural and engineered NPs) ${ }^{4,5}$. However, the results are sometimes speculative and clear distinguishing criteria are still lacking.

Isotope ratios have been widely used as powerful tracers and chronometers in geoscience, archeology, anthropology, and environmental science ${ }^{6,7}$. Stable isotopic fingerprints (or signatures) of elements in samples may contain valuable information on sources and processes which can reflect the history of the samples ${ }^{8}$. For nanotechnology, stable isotopic tracing was also expected to be a valuable tool ${ }^{9}$. The natural transformation or industrial synthetic processes of NPs may cause stable isotope fractionation ${ }^{10}$, so it is hypothesized that NPs of different origins may possess different isotopic fingerprints. Unfortunately, up to now, the use of stable isotopic fingerprints in source tracing of NPs has not succeeded. Only few studies investigated the $\mathrm{Zn}$ or Ce isotopic compositions of $\mathrm{ZnO}$ or $\mathrm{CeO}_{2}$ NPs, but they did not find distinct difference from natural and anthropogenic materials and thereby concluded that the detection of NPs in natural samples by stable isotopic tracing was not feasible ${ }^{11,12}$.

Silica nanoparticles $\left(\mathrm{SiO}_{2} \mathrm{NPs}\right)$ are the most produced engineered nanomaterials (global production volume 185-1400 kilotons in $2014^{13,14}$ ) and extensively used in construction materials, microelectronics, food and pharmaceutical industries, and consumer products ${ }^{15}$. However, $\mathrm{SiO}_{2} \mathrm{NPs}$ have also been shown to pose a significant risk to human health, e.g., inhalation of $\mathrm{SiO}_{2}$ NPs can lead to severe inflammation of the respiratory system and systemic autoimmune diseases ${ }^{16-18}$. On the other hand, natural silica is ubiquitous in the terrestrial system with $\mathrm{O}$ and $\mathrm{Si}$ being the two most abundant elements in the Earth's crust $(\mathrm{O}$ $46.6 \%$ and $\mathrm{Si} 27.7 \%$ ). Natural silica exists most commonly as quartz (the major constituent of sand) and in various living organisms. The ultrahigh background and the great diversity in silica family make it an extremely difficult task to distinguish the sources of $\mathrm{SiO}_{2} \mathrm{NPs}$ in the environment ${ }^{19}$.

Here, we report that it is possible to distinguish the sources of $\mathrm{SiO}_{2}$ NPs by their dual isotopic fingerprints. Si has three stable isotopes, ${ }^{28} \mathrm{Si}$, ${ }^{29} \mathrm{Si}$, and ${ }^{30} \mathrm{Si}$, with natural abundance $92.23 \%$, $4.67 \%$, and $3.10 \%$. O also has three stable isotopes, ${ }^{16} \mathrm{O},{ }^{17} \mathrm{O}$, and ${ }^{18} \mathrm{O}$, with ${ }^{16} \mathrm{O}$ being the most abundant $(99.76 \%)$. Notably, studies on the biogeochemical cycle of $\mathrm{Si}$ and $\mathrm{O}$ revealed that different reservoirs of $\mathrm{Si}$ and $\mathrm{O}$ in the terrestrial system have different and limited ranges of $\mathrm{Si}$ and $\mathrm{O}$ isotopic compositions ${ }^{20-}$ 22 , suggesting that the isotopic fingerprints of natural silica should be constrained in certain ranges. The objective of this study is to explore whether the industrial synthetic processes of engineered $\mathrm{SiO}_{2} \mathrm{NPs}$ lead to isotope fractionation of $\mathrm{Si}$ and $\mathrm{O}$, which enables the differentiation of engineered NPs from their naturally occurring counterparts. This work demonstrates the feasibility of source distinguishing of NPs by their isotopic fingerprints, and therefore breaks through the past perception on inherent stable isotopic tracing of NPs. It also reveals some potential for distinguishing NPs from different manufacturers and synthesized by different synthetic methods, which should be important for analysis and monitoring of nano-products.

\section{Results}

Characterization of $\mathrm{SiO}_{2}$ NPs from different sources. To test our hypothesis, we collected $\mathrm{SiO}_{2} \mathrm{NPs}$ from a variety of sources with different properties and particle sizes (see Supplementary Fig. 1 and Supplementary Table 1). For natural $\mathrm{SiO}_{2} \mathrm{NPs}$, we selected two major forms of silica, quartz (NQ) and diatomite (ND), representing geologically and biologically originating silica $(n=15)$. For engineered $\mathrm{SiO}_{2} \mathrm{NPs}$, we collected $\mathrm{SiO}_{2} \mathrm{NP}$ samples from different manufacturers located in different regions $(n=50$; see Supplementary Table 2) synthesized by three dominating methods used in the industrial production, i.e., flame pyrolysis of silicon tetrachloride $\left(\mathrm{SiCl}_{4}\right)$, precipitation of silicate solution, and sol-gel method ${ }^{23-25}$. The products of the three methods are called fumed silica (EF), precipitated silica (EP), and sol-gel silica (ES), respectively.

We first characterized $\mathrm{SiO}_{2} \mathrm{NPs}$ from diverse sources by using traditional techniques. Figure 1a shows a SEM image of standard $\mathrm{SiO}_{2}$ NPs with a monodisperse spherical shape. However, engineered $\mathrm{SiO}_{2}$ NPs had irregular shapes with considerable agglomeration (Fig. 1b, c) due to less precise shape control in the industrial production. No evident difference in shape or agglomerating behavior of engineered $\mathrm{SiO}_{2}$ NPs were observed among different synthetic methods or different manufacturers (Supplementary Fig. 2). For natural quartz and diatomite, their intact particles had characteristic shapes, i.e., NQ particles had a crystal shape consisting of flat faces with specific orientations (Supplementary Fig. 3), and ND particles could maintain the special shape of dead diatoms (Fig. 1e). However, NQ and ND also contained a large amount of defected and fragmentary particles with irregular and unfeatured shapes (Fig. 1d, f). They might be produced by natural weathering or other physical processes $^{26}$ and were not characteristic enough to differ from engineered $\mathrm{SiO}_{2}$ NPs (Supplementary Fig. 3). Therefore, microscopy measurements only cannot distinguish the sources of $\mathrm{SiO}_{2}$ NPs.

The crystal structures and chemical compositions of $\mathrm{SiO}_{2} \mathrm{NPs}$ were also characterized. The XRD yielded characteristic peaks of crystalline NQ but could not distinguish other amorphous $\mathrm{SiO}_{2}$ NPs (Fig. 1g). Furthermore, some natural and industrial processes may partially transform amorphous $\mathrm{SiO}_{2}$ NPs into crystal structures ${ }^{27,28}$. The EDX patterns showed that all $\mathrm{SiO}_{2} \mathrm{NP}$ samples were comprised of only $\mathrm{Si}$ and $\mathrm{O}$ (Fig. 1h), and the atomic ratio of $\mathrm{O}$ to $\mathrm{Si}\left(R_{\mathrm{O} / \mathrm{Si}}\right)$ ranged from $1.42 \pm 0.56$ to $3.27 \pm$ 0.57 (mean \pm s.d.; Fig. 1i). It is interesting to note that the $R_{\mathrm{O} / \mathrm{Si}}$ of $\mathrm{SiO}_{2}$ NPs did not strictly equal to the stoichiometric ratio $\mathrm{O}: \mathrm{Si}=$ 2:1. Most samples showed an excess of $\mathrm{O}$, which could be attributed to the presence of silanol $(-\mathrm{SiOH})$ groups and water (including structural and free water) ${ }^{23}$. Although engineered $\mathrm{SiO}_{2}$ NPs showed a slightly larger deviation from $R_{\mathrm{O} / \mathrm{Si}}=2$ than naturally occurring ones, this difference was not sufficient to distinguish between them. Moreover, the $R_{\mathrm{O} / \mathrm{Si}}$ may change upon the removal of water or condensation of $-\mathrm{SiOH}$ groups $^{23}$, and it showed large variations at different locations even in the same sample (Supplementary Fig. 4). Overall, the currently available measures (i.e., by shape, crystal structure, or chemical composition) are not able to distinguish the sources of $\mathrm{SiO}_{2} \mathrm{NPs}$.

Si and $\mathrm{O}$ isotopic signatures of $\mathrm{SiO}_{2} \mathrm{NPs}$. We then determined the $\mathrm{Si}$ and $\mathrm{O}$ isotopic fingerprints of $\mathrm{SiO}_{2}$ NPs from diverse sources. Here, the isotopic composition of a sample is expressed 
a

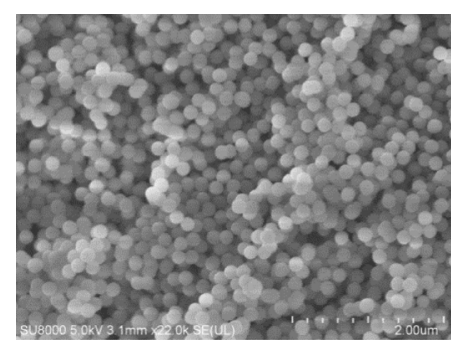

d

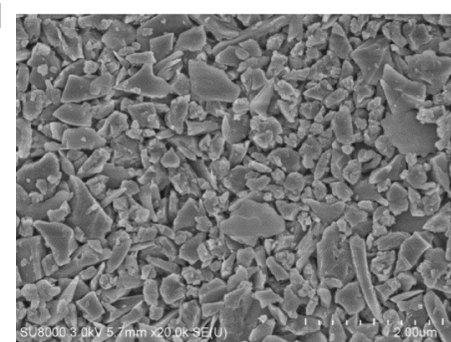

g

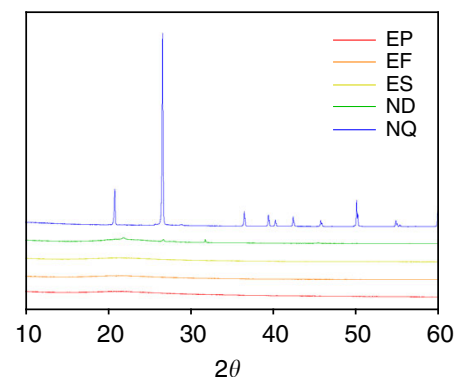

b
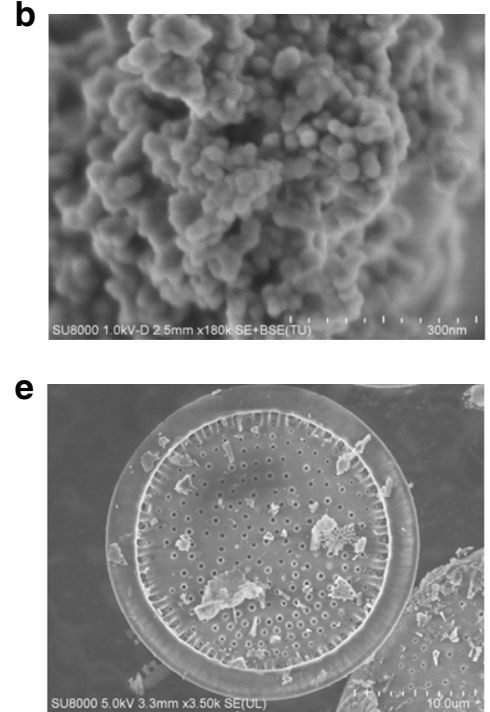

h

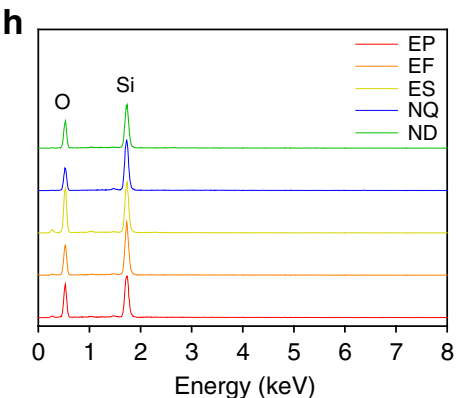

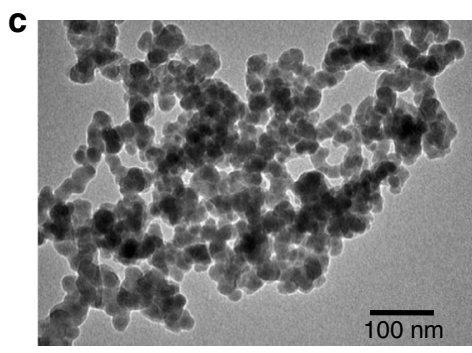
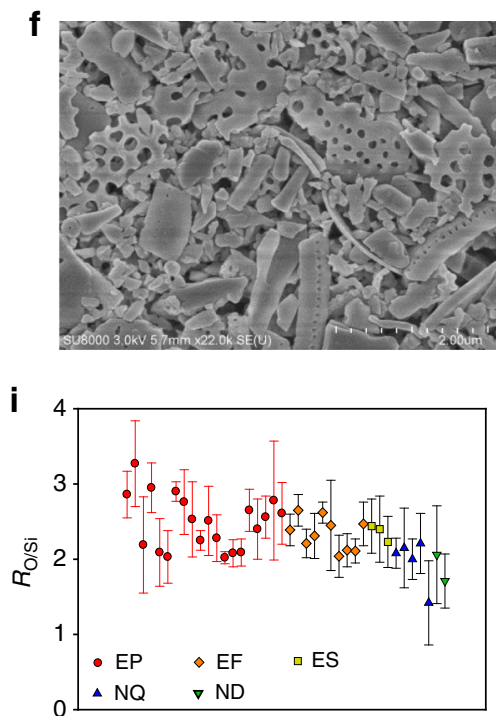

Fig. 1 Characterization of $\mathrm{SiO}_{2}$ NPs of different origins. a Typical SEM image of a $\mathrm{SiO}_{2} \mathrm{NP}$ standard. $\mathbf{b}, \mathbf{c}$ Typical SEM (b) and TEM (c) images of engineered $\mathrm{SiO}_{2}$ NPs. d SEM image of natural quartz particles. e, $\mathbf{f}$ SEM images of intact (e) and fragmentary (f) diatomite particles. $\mathbf{g}$, XRD patterns of engineered and natural $\mathrm{SiO}_{2} \mathrm{NPs}$. $\mathbf{h}$ EDX patterns of engineered and natural $\mathrm{SiO}_{2} \mathrm{NPs}$. $\mathbf{i}$ The atomic ratio of $\mathrm{O}$ to $\mathrm{Si}\left(R_{\mathrm{O} / \mathrm{Si}}\right)$ of engineered and natural $\mathrm{SiO} \mathrm{NPs}_{2}$ based on the EDX measurements. The error bars represent 2s.d. $(n=4-15)$. EP, EF, ES, ND, and NQ represent precipitated silica, fumed silica, sol-gel silica, diatomite, and quartz, respectively

as a $\delta$ value relative to a standard solution:

$$
\delta^{x} E=\left(\frac{\left({ }^{x} E /{ }^{y} E\right)_{\text {sample }}}{\left({ }^{x} E /{ }^{y} E\right)_{\text {standard }}}-1\right) \times 1000 \%
$$

where $E$ represents an element $(E=\mathrm{Si}$ or $\mathrm{O})$, and $x$ and $y$ represent mass numbers of two isotopes of the element $E$ (the $y$ normally represents the mass number of the lightest stable isotope, i.e., $y=28$ for $\mathrm{Si}$ and 16 for $\mathrm{O}$ ). The $\mathrm{Si}-\mathrm{O}$ isotopic fingerprints are described by $\delta^{30} \mathrm{Si}$ and $\delta^{18} \mathrm{O}$. High-precision Si isotope determination was achieved by multi-collector inductively coupled plasma mass spectrometry (MC-ICP-MS; 2 s.d. $=0.3 \%$ o ${ }^{29}$.

The $\mathrm{Si}$ isotopic compositions of all samples followed the massdependent isotope fractionation (Supplementary Fig. 5). As shown in Fig. 2a, natural $\mathrm{SiO}_{2} \mathrm{NPs}$ showed narrow $\delta^{30} \mathrm{Si}$ ranges $(-0.58-0.08 \%$ for NQ and $0.15-0.36 \%$ or for ND), because the isotope fractionation of $\mathrm{Si}$ in the terrestrial system is greatly limited by its low volatility, chemical inertness, and invariant bonding environment (only form $\left.\mathrm{Si}^{4+}\right)^{30,31}$. Noteworthily, we also compared our results with available data in the literature and found that the $\mathrm{Si}$ isotopic fingerprints of NQ and ND obtained here were highly consistent with those in the literature (Fig. 2b) 20,21,32-41. This demonstrated a good representiveness of our samples. Figure $2 \mathrm{~b}$ also indicates the geographical variations in $\delta^{30} \mathrm{Si}$ of NQ and ND. For engineered $\mathrm{SiO}_{2} \mathrm{NPs}$, we found a significant negative shift in $\delta^{30} \mathrm{Si}$ (i.e., enriched in light isotope) from natural NPs $\left(P<10^{-4}\right)$. Especially, EF showed a broad $\delta^{30} \mathrm{Si}$ range from $-5.74 \%$ to $-0.29 \%$ (Fig. 2a), with $-5.74 \% 0$ approaching the most negative $\delta^{30} \mathrm{Si}$ value ever found in terrestrial samples ${ }^{20}$.

Regarding $\mathrm{O}$ isotope, generally, the variations in $\delta^{18} \mathrm{O}$ were much larger than that in $\delta^{30} \mathrm{Si}$ due to higher chemical activity of $\mathrm{O}$ and larger difference in mass between ${ }^{16} \mathrm{O}$ and ${ }^{18} \mathrm{O}$. From Fig. 2c, different sources of $\mathrm{SiO}_{2} \mathrm{NPs}$ also showed different $\delta^{18} \mathrm{O}$ ranges. NQ was ${ }^{18} \mathrm{O}$-depleted relative to $\mathrm{ND}$, which also accorded with the previously published $\delta^{30} \mathrm{Si}$ data of NQ and $\mathrm{ND}$ (Fig. 2d) ${ }^{34,41}$. The $\delta^{18} \mathrm{O}$ of engineered $\mathrm{SiO}_{2} \mathrm{NPs}$ fell between that of NQ and ND $\left(P<10^{-4}\right)$. Interestingly, EF showed a wider $\delta^{30} \mathrm{Si}$ range than $\mathrm{ES}$ and $\mathrm{EP}$, but its $\delta^{18} \mathrm{O}$ range was narrower than that of ES and EP. The Si or O isotopic fingerprints of engineered $\mathrm{SiO}_{2}$ NPs showed no evident trends with the particle size (Supplementary Fig. 6). From Fig. 2b, d, although different sources of $\mathrm{SiO}_{2} \mathrm{NPs}$ showed some difference in $\mathrm{Si}$ and $\mathrm{O}$ isotopic fingerprints, it was not able to fully distinguish the different sources by using $\mathrm{Si}$ or $\mathrm{O}$ isotopes alone due to partial overlapping of the isotopic distribution ranges. Thus, we further looked into the $\mathrm{Si}-\mathrm{O} 2 \mathrm{D}$ isotopic fingerprints.

Figure $2 \mathrm{e}-\mathrm{h}$ shows the $\delta^{30} \mathrm{Si}-\delta^{18} \mathrm{O}$ plot of $\mathrm{SiO}_{2} \mathrm{NPs}$. Different sources of $\mathrm{SiO}_{2} \mathrm{NPs}$ clustered into different zones. More importantly, NQ, ND, and engineered $\mathrm{SiO}_{2} \mathrm{NPs}(\mathrm{ES}+\mathrm{EP}+$ $\mathrm{EF})$ could be fully differentiated into three isolated zones by two straight lines $\left(\delta^{18} \mathrm{O}=13 \%\right.$ and $\delta^{30} \mathrm{Si}=0.1 \%$; Fig. $\left.2 \mathrm{e}, \mathrm{f}\right)$. This revealed the possibility of distinguishing engineered $\mathrm{SiO}_{2} \mathrm{NPs}$ from their naturally occurring counterparts by the $\delta^{30} \mathrm{Si}-\delta^{18} \mathrm{O}$ 
a

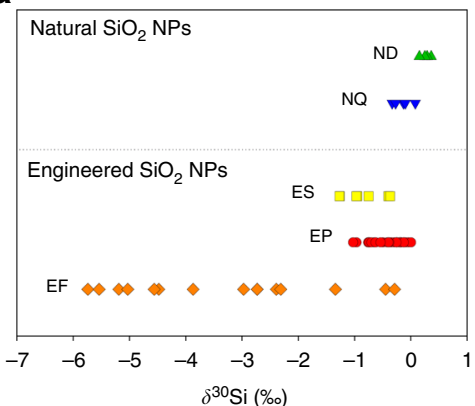

C

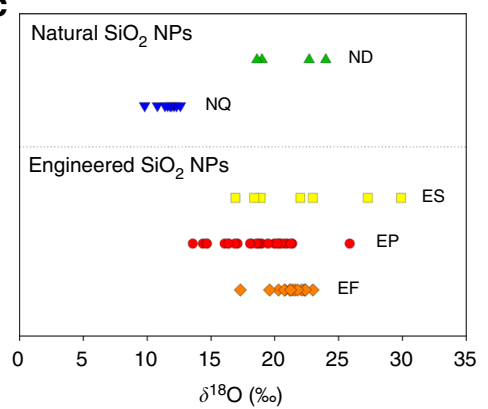

b

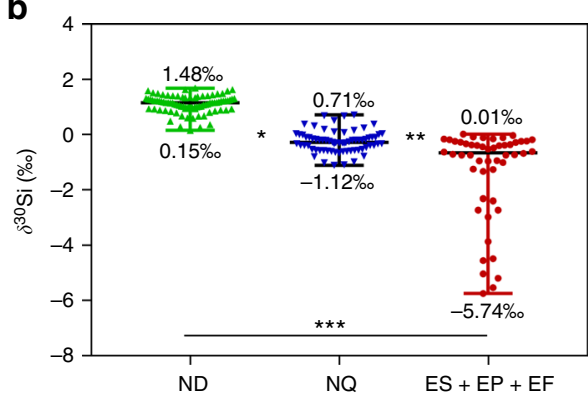

d 60

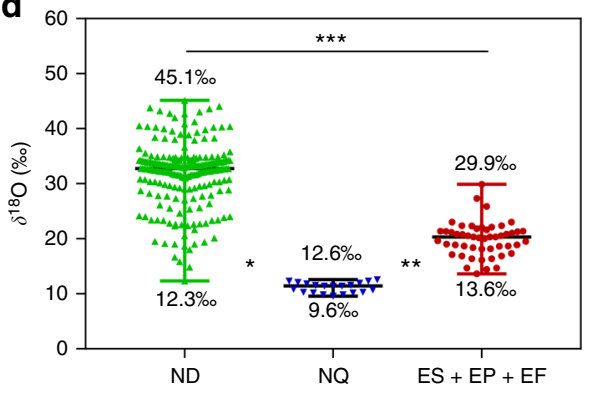

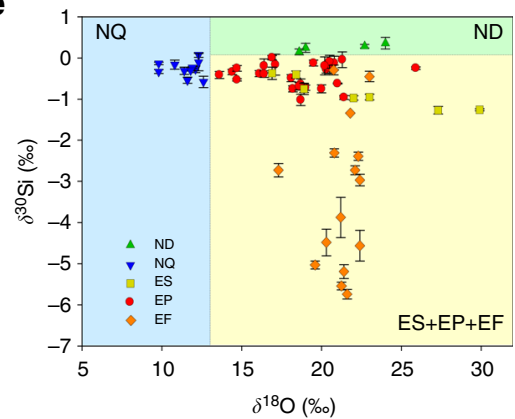

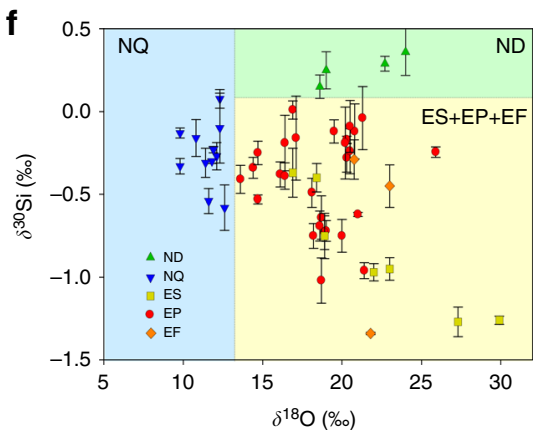

g

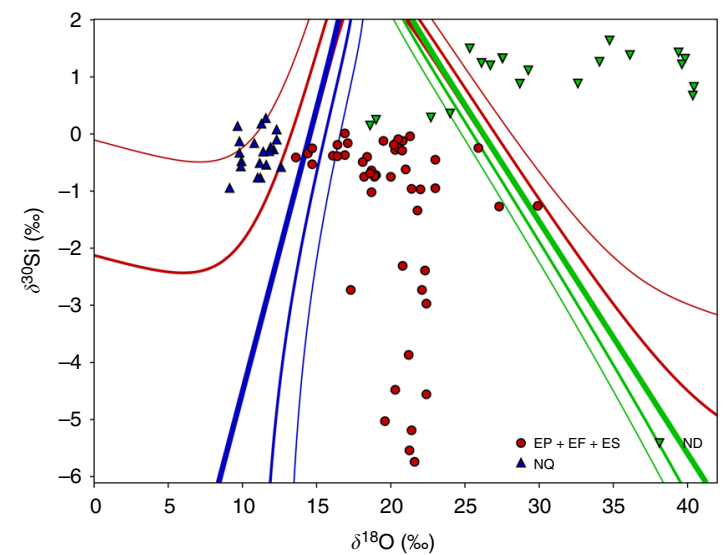

h

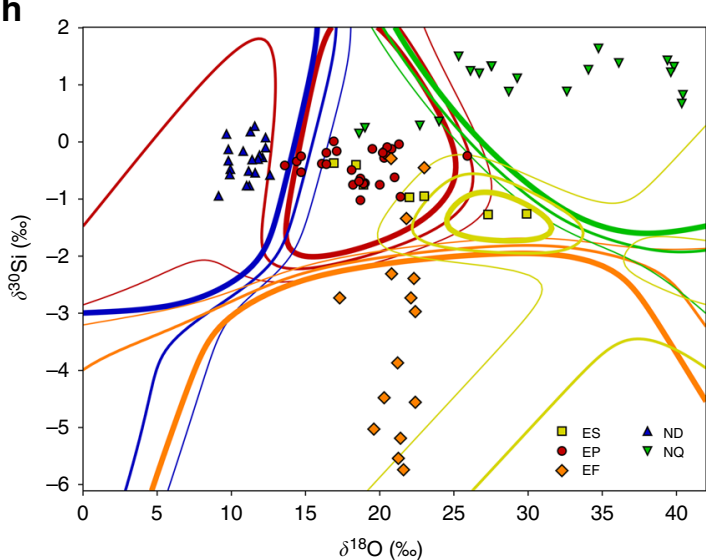

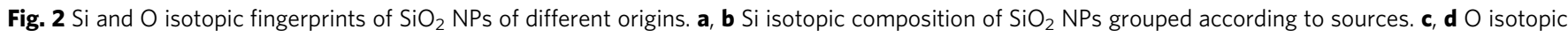
composition of $\mathrm{SiO}_{2}$ NPs grouped according to sources. The dots in $\mathbf{a}$ and $\mathbf{c}$ represent the samples tested in this study, and those in $\mathbf{b}$ and $\mathbf{d}$ include available data in the literature ${ }^{20,21,32-41}$. In $\mathbf{b}$ and $\mathbf{d},{ }^{\star} P<10^{-4},{ }^{\star \star} P<10^{-4}$, and ${ }^{\star \star \star} P<10^{-4}$. Unpaired Student's two-tailed t-test was used. e, $\mathbf{f}$, Si-O $2 \mathrm{D}$ isotopic fingerprints of $\mathrm{SiO}_{2} \mathrm{NPs}$ with source differentiation by two straight lines $\left(\delta^{18} \mathrm{O}=13 \%\right.$ and $\delta^{30} \mathrm{Si}=0.1 \%$ ). The $\mathbf{f}$ is a partial enlarged view of $\mathbf{e}$. The different colored zones represent different sources (NQ or ND or ES+EF+EP). The error bars represent 2s.d. $(n=2-5)$. $\mathbf{g}$, $\mathbf{h}$ Si-O 2D isotopic fingerprints of $\mathrm{SiO}_{2} \mathrm{NPs}$ with linear discriminant analysis (LDA) into three ( $\mathbf{g}$ ) or five classes (h). The zones defined by colored contour lines representing virtual distribution ranges of different sources given by the LDA-based classifiers. The color and thickness of the contour lines correspond to the respective sources and the probabilities of a sample being predicted to be the related class $(0.5,0.4,0.3$ for the thick, normal, and the thin one, respectively). Note that the ND and NQ samples in $\mathbf{g}$, $\mathbf{h}$ include both the real samples used in this study and pseudo-samples constructed using the $\delta^{30} \mathrm{Si}$ and $\delta^{18} \mathrm{O}$ data reported in the literature (see Supplementary Methods 1.4)

isotopic fingerprints. To make the method more precise and quantitative, we developed a machine learning model to identify the source of $\mathrm{SiO}_{2} \mathrm{NP}$ sample with linear discriminant analysis (LDA) into three, four, or five classes (see Methods). LDA is a supervised machine learning method that provides an efficient and accurate tool for multi-class classification problems ${ }^{42}$. The results for three and five classes are shown in Fig. $2 \mathrm{~g}$, h and that for four classes is given in Supplementary Fig. 7. The colored lines in Fig. 2g, h define the virtual distribution zones of different sources of $\mathrm{SiO}_{2} \mathrm{NPs}$ in $2 \mathrm{D}$ space constructed by two attributes, $\delta^{30} \mathrm{Si}$ and $\delta^{18} \mathrm{O}$, with different line thickness meaning different classification probability contours. Compared with the simple differentiation by two lines (Fig. 2e, f), the machine learning model can theoretically enable the each source of $\mathrm{SiO}_{2} \mathrm{NPs}$ to be revealed, and it is also easy to be applied to other types of NPs with more than two elements. In this way, we have calculated the probabilities of sources for all $\mathrm{SiO}_{2} \mathrm{NP}$ samples (see Supplementary Tables 3-5), and the source discrimination results are given in Table 1 and Supplementary Table 6-7 based on the most probable source. The total discrimination accuracy between engineered and natural $\mathrm{SiO}_{2} \mathrm{NPs}$ was beyond 93.3\%, indicating that this technique was highly accurate and reliable. Specifically, in terms of engineered NPs, the discrimination accuracy between $\mathrm{EP}$ and $\mathrm{EF}$ was $>80 \%$, but ES could not be well differentiated from other sources. Therefore, this technique showed a strong ability of distinguishing between engineered and natural NPs, 
while its potential to distinguish the different synthetic methods of engineered NPs needs to be further improved.

Insights into the synthetic pathways of engineered $\mathrm{SiO}_{2} \mathrm{NPs}$. To better understand the difference in the isotopic fingerprints of $\mathrm{SiO}_{2} \mathrm{NPs}$, we investigated the industrial synthetic pathways of engineered $\mathrm{SiO}_{2}$ NPs. As shown in Fig. 3, the industrial production of $\mathrm{SiO}_{2}$ NPs, including EF, ES, and EP pathways, involves complex chemical and physical processes. All chemical reactions and materials in the synthesis of engineered $\mathrm{SiO}_{2} \mathrm{NPs}$ are listed in Supplementary Table 8. Natural quartz is the most commonly used starting material (only in few cases diatomite is used), and there are five important intermediate substances, ferrosilicon $\left(\mathrm{Fe}_{x} \mathrm{Si}_{y}\right)$, industrial $\mathrm{Si}$, silicon tetrachloride $\left(\mathrm{SiCl}_{4}\right)$, tetraethoxysilane (TEOS), and sodium silicate $\left(\mathrm{Na}_{2} \mathrm{SiO}_{3}\right)$. For $\mathrm{Si}$ isotopes, compared with the raw material NQ, all products (EF, ES, and EP) were enriched in the light Si isotope (Fig. 2a), which followed the kinetic isotope fractionation mechanism ${ }^{8}$. It should

\begin{tabular}{|c|c|c|c|c|c|c|c|}
\hline \multirow[t]{2}{*}{ Sample } & \multirow[t]{2}{*}{ Total } & \multicolumn{5}{|c|}{ Source identified ${ }^{b}$} & \multirow[t]{2}{*}{ Accuracy } \\
\hline & & EP & EF & ES & NQ & ND & \\
\hline $\mathrm{SiO}_{2} \mathrm{NPs}$ & 90 & \multicolumn{5}{|c|}{ Number of correct: $84^{c}$} & $93.3 \%$ \\
\hline $\mathrm{L}$ Engineered NPs & 50 & $49^{d}$ & & & $1^{e}$ & & $98.0 \%$ \\
\hline $\mathrm{L} E P$ & 28 & 27 & 0 & 0 & 1 & 0 & $96.4 \%$ \\
\hline LEF & 15 & 3 & 12 & 0 & 0 & 0 & $80.0 \%$ \\
\hline LES & 7 & 5 & 0 & 2 & 0 & 0 & $28.6 \%$ \\
\hline L Natural NPs & 40 & $5^{d}$ & $35^{e}$ & & & & $87.5 \%$ \\
\hline L NQ & 20 & 0 & 0 & 0 & 20 & 0 & $100 \%$ \\
\hline L ND & 20 & 5 & 0 & 0 & 0 & 15 & $75.0 \%$ \\
\hline
\end{tabular}

a Engineered NPs were collected from 14 manufacturers located in 6 different regions. Natural NPs included both real and pseudo-samples (see Supplementary Section 1.4). For real samples, NQ samples were collected from 9 manufactures and ND samples were from 3 manufactures. More detals about saples are given in Supplementary Table 1 and 2 . The sourc 6 .

bThe machine learning model could give a probability value for each candidate source (see Supplementary Table 3), and the statistics in this table was based on the most probable source. c The "number of correct" means the number of samples with correct discrimination result between engineered and natural $\mathrm{SiO}_{2} \mathrm{NP}$.

The total number of engineered $\mathrm{SiO}_{2} \mathrm{NPs}$ identified (EP + EF + ES).

e The total number of natural $\mathrm{SiO}_{2} \mathrm{NPs}$ identified (NQ + ND). be noted that the isotope fractionation caused by a reaction/ process is dependent on the relative fraction reacted ${ }^{8}$. In industrial production, the highest possible relative fraction reacted is always pursued to achieve high yields, which can actually erase the isotope fractionation in products ${ }^{8}$. Comparing the routes to EF and ES (Fig. 3), EF showed a much more negative $\delta^{30}$ Si range than ES, suggesting that the particular reaction step of EF, i.e., the flame pyrolysis of $\mathrm{SiCl}_{4}$ (reaction 10), might dominate the $\mathrm{Si}$ isotope variations of $\mathrm{EF}$. This was also evidenced by the wide $\delta^{30} \mathrm{Si}$ range of EF produced from the same precursor $\left(\mathrm{SiCl}_{4}\right)$. The wide $\delta^{30} \mathrm{Si}$ range of $\mathrm{EF}$ could be explained by the large isotopic enrichment factor and highly uncertain relative fraction reacted of the reaction 10 (see Supplementary Section 2.1 for detailed discussion). ES and EP showed small shift in $\delta^{30}$ Si from NQ and limited $\delta^{30} \mathrm{Si}$ ranges, suggesting that the sol-gel and precipitation processes caused only little isotope fractionation.

For $\mathrm{O}$ isotopes, in contrast to $\mathrm{Si}$ isotopes, all products (EF, ES, and EP) were enriched in the heavy isotope relative to NQ (Fig. 2c), which could not be explained by the kinetic isotope fractionation. Note that the raw material NQ was not the only source of $\mathrm{O}$ in the synthetic pathways. Thus, it is rational to infer that the enrichment of heavy $\mathrm{O}$ isotope in engineered $\mathrm{SiO}_{2} \mathrm{NPs}$ might result from the introduction of external ${ }^{18} \mathrm{O}$-enriched substances (e.g., $\mathrm{O}_{2}$ in reaction $\mathbf{1 0}$, alcohol in reactions $\mathbf{8}$ and $\mathbf{9}$, and $\mathrm{NaOH}$ in reaction 5; see Supplementary Table 8). The industrial $\mathrm{O}_{2}$ gas normally derives from atmospheric $\mathrm{O}_{2}$ that is isotopically heavier $\left(24.15 \pm 0.05 \%{ }^{43}\right)$ than NQ, causing EF being enriched in ${ }^{18} \mathrm{O}$. For ES and EP, the explanation for their $\mathrm{O}$ isotope variations is still not very clear due to the complex $\mathrm{O}$ sources and unknown $\mathrm{O}$ isotopic compositions of industrial alcohol and $\mathrm{NaOH}$, which needs to be verified in future studies. The uncertain $\mathrm{O}$ sources might also be the reason why ES and EP had wider $\delta^{18} \mathrm{O}$ ranges than $\mathrm{EF}$.

Differentiation of engineered $\mathrm{SiO}_{2}$ NPs according to manufacturers. To further recognize the power of this technique, we classified the isotopic fingerprints of engineered $\mathrm{SiO}_{2} \mathrm{NPs}$ according to manufacturers (Fig. 4). Interestingly, we found that the engineered $\mathrm{SiO}_{2} \mathrm{NPs}$ from different manufacturers indeed showed some characteristic $\mathrm{Si}$ and $\mathrm{O}$ isotopic fingerprints. Especially for EP (Fig. 4a, b) and ES (Fig. 4c, d), the Si and O isotopic fingerprints of products from different manufacturers

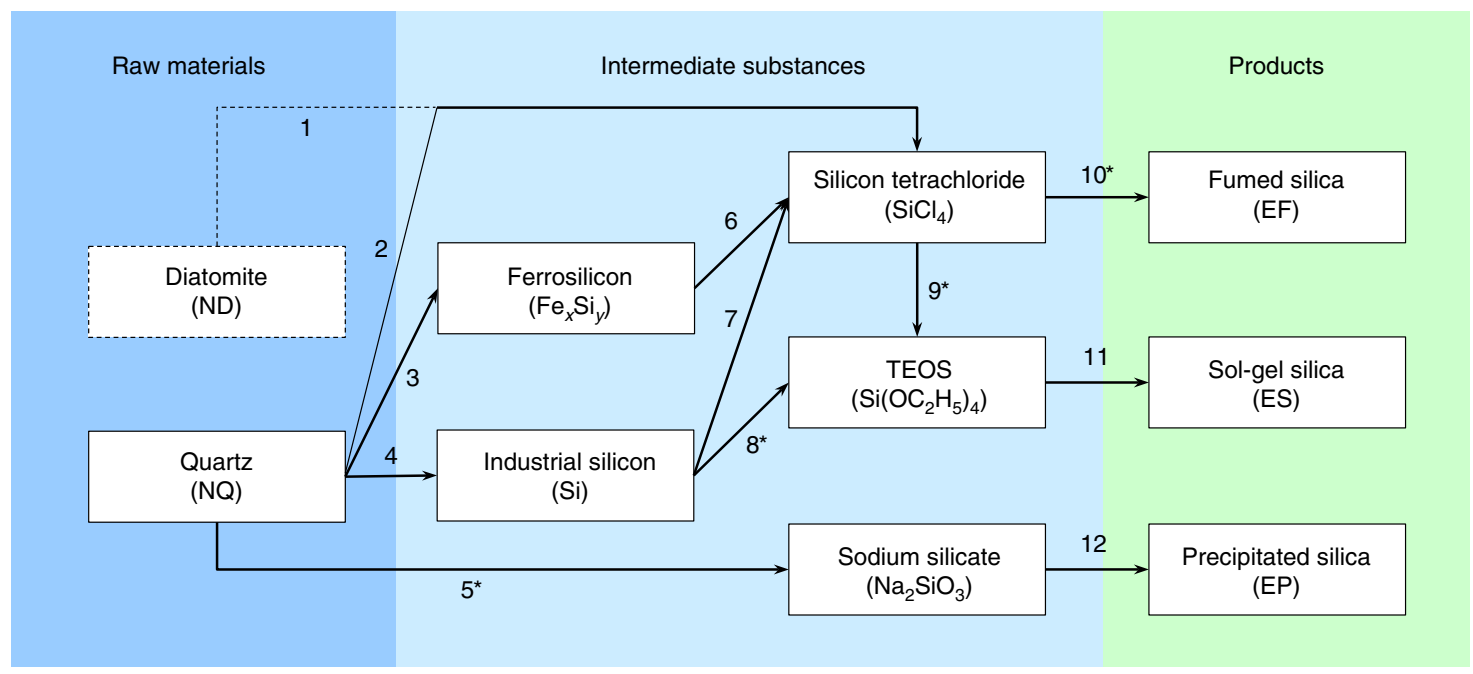

Fig. 3 Scheme showing the industrial synthetic pathways of engineered $\mathrm{SiO}_{2} \mathrm{NPs}$. The reaction equations 1-12 are given in Supplementary Table 8. The key reactions that may cause significant isotope fractionation of $\mathrm{Si}$ or $\mathrm{O}$ are marked with asterisks. The dashed line represent a potential but not commonly used route 
a

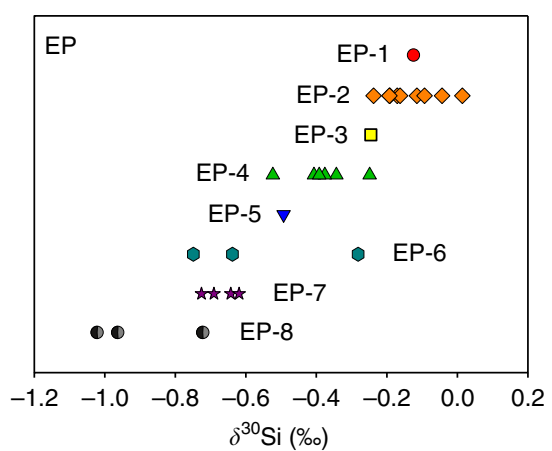

C
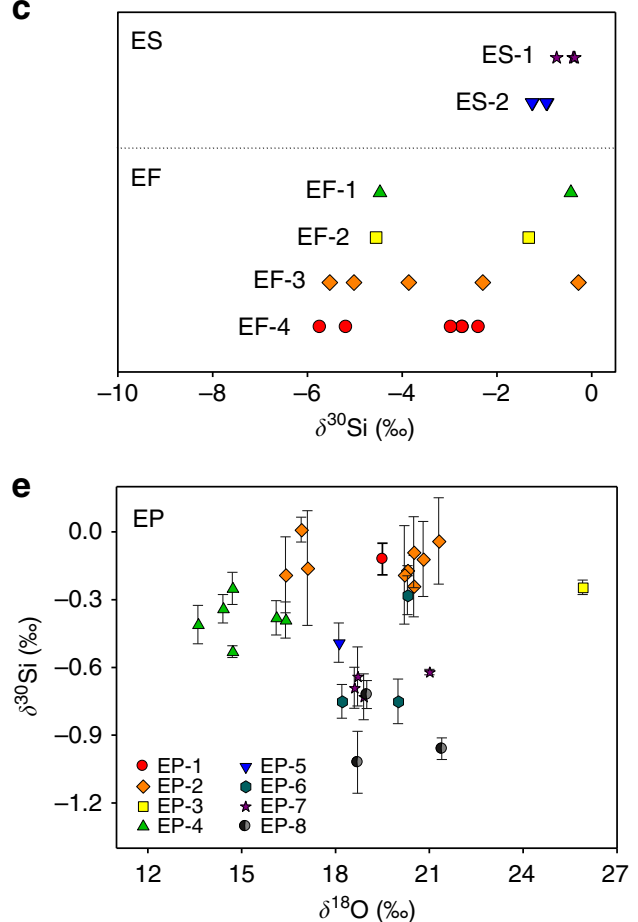

b

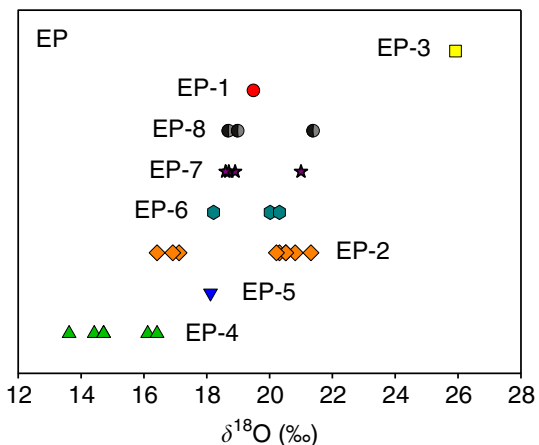

d

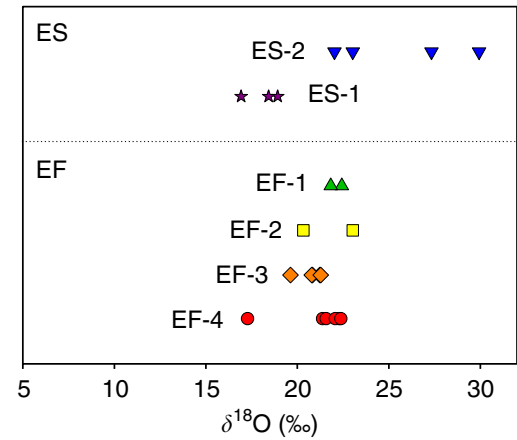

f

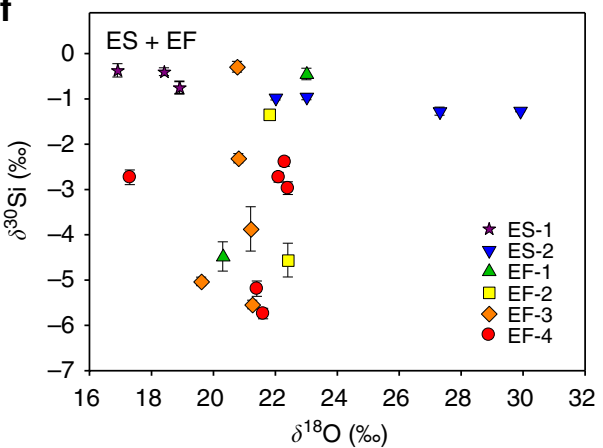

Fig. $4 \mathrm{Si}$ and $\mathrm{O}$ isotopic fingerprints of engineered $\mathrm{SiO}_{2} \mathrm{NPs}$ synthesized by different methods and from different manufacturers. a, b $\mathrm{Si}$ (a) and $\mathrm{O}$ (b) isotopic compositions of precipitated $\mathrm{SiO}_{2} \mathrm{NPs}$ (EP) grouped according to manufacturers. $\mathbf{c}, \mathbf{d} \mathrm{Si}$ (c) and $\mathrm{O}$ (d) isotopic compositions of sol-gel and fumed $\mathrm{SiO}_{2} \mathrm{NPs}$ (ES and EF) grouped according to manufacturers. e Si-O 2D isotopic fingerprints of EP. f Si-O 2D isotopic fingerprints of ES and EF. The error bars in $\mathrm{e}$ and $\mathrm{f}$ represent $2 \mathrm{~s}$.d. in parallel measurements $(n=2-5)$

distributed in different ranges, probably resulting from the variation in $\mathrm{Si}$ and $\mathrm{O}$ isotopic composition of the raw material. This enabled the potential differentiation of EP and ES products from different manufacturers by their $\mathrm{Si}-\mathrm{O} 2 \mathrm{D}$ isotopic fingerprints (Fig. 4e, f). For EF, the products from different manufacturers also showed some difference in $\mathrm{Si}$ and $\mathrm{O}$ isotopic fingerprints (Fig. 4c, d), but it was not large enough to differentiate among different manufacturers (Fig. 4f). Furthermore, we found that the isotope fractionation degree during the manufacturing process varied among different manufacturers (Supplementary Fig. 8), suggesting that the isotope fractionation was also affected by the manufacturing conditions. Overall, this technique is not only capable of differentiating the sources of $\mathrm{SiO}_{2} \mathrm{NPs}$, but also shows some capability to identify their manufacturers.

Application to real samples. We finally applied this technique to analyze consumer products that claimed to contain $\mathrm{SiO}_{2} \mathrm{NPs}$, including several types of toothpastes (TP), inorganic filter membranes (IFM), and nanoquartz coating (NQC). We extracted $\mathrm{SiO}_{2}$ NPs from these consumer products (Supplementary
Table 9), measured their Si-O isotopic fingerprints, and calculated their probabilities of sources using the three-, four-, and five-class LDA-based classifiers (Supplementary Fig. 9 and Supplementary Table 10-12). It was found that the $\mathrm{SiO}_{2}$ NPs in TP samples were highly probable to originate from EP or ES (probability 90.0-96.0\% for EP + ES in four-class LDA), which accorded with the fact that precipitated silica is commonly used as an abrasive and thickening agent in toothpastes due to its abrasive nature. The $\mathrm{SiO}_{2}$ NPs in IFM samples probably originated from EP or NQ (probability $52.5-58.4 \%$ for EP and $37.1-43.9 \%$ for NQ in five-class LDA), and that in the NQC sample most probably came from NQ (probability > 59.5\%), which was consistent with the production description provided by the factory. These results showed the usefulness of the technique in real sample analysis.

\section{Discussion}

Our results have revealed the possibility of isotopic fingerprints in source tracing of NPs, which actually breaks through the previous knowledge on stable isotopic tracing of $\mathrm{NPs}^{11,12}$. It should be 
stressed that this technique is based on the inherent isotopic fingerprints of NPs and thus should be suitable for application in complex systems (e.g., natural environment, biological, and industrial systems). The difference in isotopic fingerprints of different sources of $\mathrm{SiO}_{2}$ NPs are deemed to result from the $\mathrm{Si}$ and $\mathrm{O}$ isotope fractionation during the manufacturing process of engineered $\mathrm{SiO}_{2} \mathrm{NPs}$ as well as the different isotopic compositions of raw materials. The combined use of $\mathrm{Si}$ and $\mathrm{O}$ isotopic signatures provide more information on the sources of NPs, enabling a more effective source differentiation than using isotopes of one single element. Note that most types of engineered NPs (e.g., $\mathrm{TiO}_{2}, \mathrm{Fe}_{x} \mathrm{O}_{y}, \mathrm{ZrO}_{2}$, quantum dots) have multiple elements with multiple isotopes. As long as their naturally occurring counterparts have relatively constant isotopic ranges and that the manufacturing process of engineered NPs leads to a stable isotope fractionation, it is possible to differentiate the sources of NPs by their isotopic fingerprints. Considering that many elements have constrained isotopic composition ranges in the terrestrial system, this technique has the potential to emerge as a universal tool for source distinguishing of NPs.

The correct distinguishing of sources of NPs in samples is an important prerequisite for a proper risk assessment of engineered NPs. Although the environmental concentrations of engineered NPs are currently very low compared with their naturally occurring counterparts, an exponential increase is predicted due to their rising usage and disposal amounts ${ }^{44,45}$. The distinguishable isotopic fingerprints reveal a possible approach to identify whether the target NP samples are anthropogenic or naturally occurring for properly assessing the impact of NP exposure. Furthermore, the potential of distinguishing the manufacturer and synthetic methods of engineered NPs, which is very difficult to be accomplished by other techniques, would be of high value for analysis and monitoring of nano-products.

By far, the shortage of this technique is that, due to the great diversity of silica family, it does not cover some rare types of $\mathrm{SiO}_{2}$ NPs; either, it is difficult to predict whether the future technical improvement in the production of engineered $\mathrm{SiO}_{2} \mathrm{NPs}$ will significantly alter their isotopic fingerprints. With regards to more types of NPs, for some elements it is still difficult to precisely measure their stable isotopic compositions ${ }^{46}$. For realworld samples, intensive sample purification is required prior to high-precision stable isotopic analysis. Therefore, this technique still needs continuous improvement in future applications. Future works will be needed to: (1) get deeper insights into the isotope fractionation mechanisms during the natural and engineering processes of NPs, (2) further optimize the mathematical model by including more types of sources and a larger size of sample set to make it more accurate and practical, and (3) extend the technique to more types of NPs.

\section{Methods}

Characterization of $\mathrm{SiO}_{2}$ NPs. SEM images were capture on a Hitachi S-3000N scanning electron microscope (Tokyo, Japan) equipped with an energy dispersive $\mathrm{X}$-ray spectroscope operating at an accelerating voltage of $15 \mathrm{kV}$. TEM measurements were performed on a 300-mesh copper grid using a JEM 2100 transmission electron microscope (JEOL, Japan) operating at 200kV. XRD analyses were performed using a PANalytical X'Pert X-ray diffractometer (Almelo, Netherlands) at a scanning rate of $10 \% \mathrm{~min}$. XRF analyses were performed on an ARL Perform'X $\mathrm{X}$-ray fluoroscope (ThermoFisher, Switzerland). The elemental concentrations were measured by an Agilent 7500 inductively coupled plasma mass spectrometer (Santa Clara, CA, USA).

Sample preparation for $\mathbf{S i}$ isotopic analysis. For $\mathrm{Si}$ isotopic analysis, the sample was digested using alkali fusion method with solid $\mathrm{NaOH}^{47,48}$. Briefly, $5-10 \mathrm{mg}$ of powdered samples were mixed with $200 \mathrm{mg}$ of solid $\mathrm{NaOH}$ in a $30 \mathrm{~mL}$ Ag crucible, and then the mixture was heated at $1000 \mathrm{~K}$ in a muffle furnace. After cooling down to room temperature, the fusion cake was dissolved with $10 \mathrm{~mL}$ of water followed by being stored in dark for $24 \mathrm{~h}$. The final solution was transferred to a $50 \mathrm{~mL}$ centrifuge tube, and then its $\mathrm{pH}$ was adjusted to $\sim 2$ using $\mathrm{HCl}$ solution. The blank $\mathrm{Ag}$ crucible and solid $\mathrm{NaOH}$ were also analyzed using the same procedures to ensure that they had no interference to the measurement of Si isotopic composition.

To eliminate the interference from sample matrix, cation-exchange chromatography was employed to purify the sample as reported previously 47,49 The cation-exchange resin (DOWEX 50-X12, 200-400 mesh) was first activated for $12 \mathrm{~h}$ in dark and packed to a $1.8 \mathrm{~mL}$ resin bed. Then, the resin was repeatedly rinsed with $\mathrm{HCl}$ and $\mathrm{HNO}_{3}$ solution followed by being eluted to neutral $\mathrm{pH}$ with water. Afterwards, $2 \mathrm{~mL}$ of sample at a Si concentration of $2 \mathrm{mg} / \mathrm{L}$ was loaded to the cationexchange column and eluted with $2 \mathrm{~mL}$ of water. The final solution can be directly analyzed by multi-collector inductively coupled plasma mass spectrometry (MC-ICP-MS). The recovery of Si during the sample preparation process was $>95 \%$. The whole sample preparation procedures were tested with two Si isotope standard reference materials (NIST SRM-8546 and IRMM-017) to verify that no interference was caused to the $\mathrm{Si}$ isotope measurement.

Si isotopic analysis. The $\mathrm{Si}$ isotopic composition was measured by a Nu Plasma II MC-ICP-MS (Wrexham, UK) equipped with a DeSolvation Nebulizer System

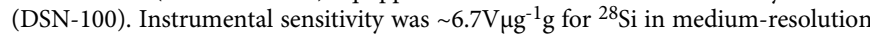
mode. The sample was introduced in dry mode using a PFA nebulizer at a flow rate of $70 \mu \mathrm{L} / \mathrm{min}$ with a signal intensity of ${ }^{28} \mathrm{Si}$ in the range of $3.6-7.5 \mathrm{~V}$. The optimized instrumental parameters are listed in Supplementary Table 13. The signal intensities of blank $\mathrm{HCl}$ and $\mathrm{NaOH}$ pretreated using the same procedures as mentioned above were less than $0.04 \mathrm{~V}$, indicating that they caused no interference to the $\mathrm{Si}$ isotope ratio measurements. After each measurement, a rinse with $\mathrm{HCl}$ solution $(\mathrm{pH}=2)$ for $>120$ s was used to reduce the background signal intensity to $<0.03 \mathrm{~V}$ At least two parallel measurements were performed for all samples.

The mass bias was corrected by the standard-sample-standard bracketing method. The $\mathrm{Si}$ isotope composition in a sample is expressed by a $\delta$ value $\left(\delta^{30} \mathrm{Si}\right.$ and $\delta^{29} \mathrm{Si}$ ) relative to the standard NIST SRM-8546:

$$
\begin{aligned}
& \delta^{29} \mathrm{Si}=\left(\frac{\left({ }^{29} \mathrm{Si} /{ }^{28} \mathrm{Si}\right)_{\text {sample }}}{\left({ }^{29} \mathrm{Si} /{ }^{28} \mathrm{Si}\right)_{\text {standard }}}-1\right) \times 1000 \% \\
& \delta^{30} \mathrm{Si}=\left(\frac{\left({ }^{30} \mathrm{Si} /{ }^{28} \mathrm{Si}\right)_{\text {sample }}}{\left(\left({ }^{30} \mathrm{Si} /{ }^{28} \mathrm{Si}\right)_{\text {standard }}\right.}-1\right) \times 1000 \%
\end{aligned}
$$

Two standard reference materials (NIST SRM-8546 and IRMM-017) were used to validate the method. In each sample batch, the difference of signal intensity between standard and sample solutions was $<10 \%$. A $\delta^{30} \mathrm{Si}$ value of $-(0.004 \pm$ $0.17) \%$ (mean \pm s.d., $n=27$ ) was obtained with a NIST SRM-8546 solution, and the $\delta^{30}$ Si value of IRMM- 017 was $-(1.43 \pm 0.16) \%$ (mean \pm s.d., $\left.n=22\right)$, which was very close to the previously reported results ${ }^{29,48}$, proving that our method was highly accurate and precise.

O isotopic analysis. $\mathrm{O}$ isotopic ratios were measured by the bromine pentafluoride method ${ }^{50}$. Briefly, to liberate oxygen from $\mathrm{SiO}_{2}, \mathrm{BrF}_{5}$ was used to react with the sample under high vacuum $\left(<2 \times 10^{-3} \mathrm{~Pa}\right)$ and high temperature $\left(550^{\circ} \mathrm{C}\right)$ for more than six hours. Then, the product $\left(\mathrm{O}_{2}\right)$ collected by a sample hose with a $5 \AA$ molecular sieve was directly subjected to $\mathrm{O}$ isotopic ratio measurement using a Thermo 253 Plus isotope ratio mass spectrometer (IR-MS). In each batch, a standard reference material (GBW04421) was inserted into five samples to verify that no $\mathrm{O}$ isotope fractionation occurred in this process. The $\mathrm{O}$ isotopic composition in a sample was expressed by a $\delta^{18} \mathrm{O}$ value:

$$
\delta^{18} O_{\text {sample-standard }}=\left(\frac{\left({ }^{18} \mathrm{O} /{ }^{16} \mathrm{O}\right)_{\text {sample }}}{\left({ }^{18} \mathrm{O} /{ }^{16} \mathrm{O}\right)_{\text {standard }}}-1\right) \times 1000 \%
$$

To facilitate inter-laboratory data comparison, the $\mathrm{O}$ isotope ratios are also usually reported relative to the "Vienna Standard Mean Ocean Water" (VSMOW). The calculation formula is as follows:

$$
\delta^{18} \mathrm{O}_{\mathrm{SA}-\mathrm{VSMOW}}=\frac{\left(\delta^{18} \mathrm{O}_{\mathrm{SA}-\mathrm{RE}}+1000\right)\left(\delta^{18} \mathrm{O}_{\mathrm{ST}-\mathrm{VSMOW}}+1000\right)}{\left(\delta^{18} \mathrm{O}_{\mathrm{ST}-\mathrm{RE}}+1000\right)}-1000(\%)
$$

where SA represents the sample, ST represents the standard reference material (GBW04421), and RE represents the reference gas $\left(\mathrm{O}_{2}\right)$ used in IR-MS. The $\delta^{30} \mathrm{Si}$ value of GBW04421 was $(10.92 \pm 0.32) \%$ (mean \pm s.d., $n=13$ ) relative to VSMOW.

Machine learning model. In order to mathematically distinguish the potential sources of $\mathrm{SiO}_{2}$ NPs by isotopic fingerprints, we built classifiers with linear discriminant analysis (LDA). LDA is a supervised machine learning method that provides an efficient and accurate tool for multi-class classification problems ${ }^{42}$. The experimental isotopic fingerprint data for the three to five classes of sources, combining with the additional literature data for NQ and ND (Supplementary Section 1.4), formed the training set. Data preparation and analysis were performed using our in-house Python scripts, and the LDA implementation was based on the scikit-learn (0.19.0) package ${ }^{51}$. 
Reporting Summary. Further information on experimental design is available in the Nature Research Reporting Summary linked to this article.

\section{Data availability}

The data that support the findings of this study are available from the corresponding author upon reasonable request.

\section{Code availability}

The code that support the findings of this study are available from the corresponding author upon reasonable request.

Received: 27 November 2018 Accepted: 19 March 2019

Published online: 08 April 2019

\section{References}

1. Auffan, M. et al. Towards a definition of inorganic nanoparticles from an environmental, health and safety perspective. Nat. Nanotechnol. 4, 634-641 (2009).

2. Guinee, J. B., Heijungs, R., Vijver, M. G. \& Peijnenburg, W. J. G. M. Setting the stage for debating the roles of risk assessment and life-cycle assessment of engineered nanomaterials. Nat. Nanotechnol. 12, 727-733 (2017).

3. Praetorius, A. et al. Single-particle multi-element fingerprinting (spMEF) using inductively-coupled plasma time-of-flight mass spectrometry (ICPTOFMS) to identify engineered nanoparticles against the elevated natural background in soils. Environ. Sci. Nano 4, 307-314 (2017).

4. Gondikas, A. et al. Where is the nano? Analytical approaches for the detection and quantification of $\mathrm{TiO}_{2}$ engineered nanoparticles in surface waters. Environ. Sci. Nano 5, 313-326 (2018).

5. Maher, B. A. et al. Magnetite pollution nanoparticles in the human brain Proc. Natl. Acad. Sci. USA 113, 10797-10801 (2016).

6. Baskaran, M. Handbook of Environmental Isotope Geochemistry. (Springer, 2011).

7. Yin, Y. et al. Isotope tracers to study the environmental fate and bioaccumulation of metal-containing engineered nanoparticles: techniques and applications. Chem. Rev. 117, 4462-4487 (2017).

8. Wiederhold, J. G. Metal stable isotope signatures as tracers in environmental geochemistry. Environ. Sci. Technol. 49, 2606-2624 (2015).

9. Gulson, B. \& Wong, H. Stable isotopic tracing-a way forward for nanotechnology. Environ. Health Perspect. 114, 1486-1488 (2006).

10. $\mathrm{Lu}, \mathrm{D}$. et al. Stable silver isotope fractionation in the natural transformation process of silver nanoparticles. Nat. Nanotechnol. 11, 682-686 (2016).

11. Larner, F. \& Rehkämper, M. Evaluation of stable isotope tracing for $\mathrm{ZnO}$ nanomaterials-New constraints from high precision isotope analyses and modeling. Environ. Sci. Technol. 46, 4149-44158 (2012).

12. Laycock, A., Coles, B., Kreissig, K. \& Rehkämper, M. High precision ${ }^{142} \mathrm{Ce} /{ }^{140} \mathrm{Ce}$ stable isotope measurements of purified materials with a focus on $\mathrm{CeO}_{2}$ nanoparticles. J. Anal. At. Spectrom. 31, 297-302 (2016).

13. Pulit-Prociak, J. \& Banach, M. Silver nanoparticles-a material of the future...? Open Chem. 14, 76-91 (2016).

14. Keller, A. A. \& Lazareva, A. Predicted Releases of Engineered Nanomaterials: From Global to Regional to Local. Environ. Sci. Technol. Lett. 1, 65-70 (2014).

15. Zou, H., Wu, S. \& Shen, J. Polymer/silica nanocomposites: preparation, characterization, properties, and applications. Chem. Rev. 108, 3893-3957 (2008).

16. Yamashita, K. et al. Silica and titanium dioxide nanoparticles cause pregnancy complications in mice. Nat. Nanotechnol. 6, 321-328 (2011).

17. Yassin, A., Yebesi, F. \& Tingle, R. Occupational exposure to crystalline silica dust in the United States, 1988-2003. Environ. Health Perspect. 113, 255-260 (2005).

18. Adams, L. K., Lyon, D. Y. \& Alvarez, P. J. Comparative eco-toxicity of nanoscale $\mathrm{TiO}_{2}, \mathrm{SiO}_{2}$, and $\mathrm{ZnO}$ water suspensions. Water Res. 40, 3527-3532 (2006).

19. Montaño, M. D., Majestic, B. J., Jämting, Å. K., Westerhoff, P. \& Ranville, J. F. Methods for the detection and characterization of silica colloids by microsecond spICP-MS. Anal. Chem. 88, 4733-4741 (2016).

20. Basile-Doelsch, I., Meunier, J. D. \& Parron, C. Another continental pool in the terrestrial silicon cycle. Nature 433, 399-402 (2005).

21. Douthitt, C. The geochemistry of the stable isotopes of silicon. Geochim. Cosmochim. Acta 46, 1449-1458 (1982).

22. Dawson, T. E. \& Siegwolf, R. T. Using stable isotopes as indicators, tracers, and recorders of ecological change: some context and background. Terrest. Ecol. 1, 1-18 (2007).

23. Musić, S., Filipović-Vinceković, N. \& Sekovanić, L. Precipitation of amorphous $\mathrm{SiO}_{2}$ particles and their properties. Braz. J. Chem. Eng. 28, 89-94 (2011).
24. Swihart, M. T. Vapor-phase synthesis of nanoparticles. Curr. Opin. Colloid Interf. Sci. 8, 127-133 (2003)

25. Rahman, I. A. \& Padavettan, V. Synthesis of silica nanoparticles by sol-gel: size-dependent properties, surface modification, and applications in silicapolymer nanocomposites-a review. J. Nanomater. 2012, 8-22 (2012).

26. Gaillardet, J., Dupré, B., Louvat, P. \& Allegre, C. Global silicate weathering and $\mathrm{CO}_{2}$ consumption rates deduced from the chemistry of large rivers. Chem. Geol. 159, 3-30 (1999).

27. Bansal, V., Ahmad, A. \& Sastry, M. Fungus-mediated biotransformation of amorphous silica in rice husk to nanocrystalline silica. J. Am. Chem. Soc. 128, 14059-14066 (2006).

28. Ediz, N., Bentli, İ. \& Tatar, İ. Improvement in filtration characteristics of diatomite by calcination. Int. J. Miner. Proc. 94, 129-134 (2010).

29. Lu, D. et al. Natural silicon isotopic signatures reveal the sources of airborne fine particulate matter. Environ. Sci. Technol. 52, 1088-1095 (2018).

30. Savage, P. S., Armytage, R. M., Georg, R. B. \& Halliday, A. N. High temperature silicon isotope geochemistry. Lithos 190, 500-519 (2014).

31. Sridhar, K., Jackson, M. \& Clayton, R. Quartz oxygen isotopic stability in relation to isolation from sediments and diversity of source 1. Soil Sci. Soc. Am. J. 39, 1209-1213 (1975).

32. Reynolds, J. H. \& Verhoogen, J. Natural variations in the isotopic constitution of silicon. Geochim. Cosmochim. Acta 3, 224-234 (1953).

33. Matsuhisa, Y., Goldsmith, J. R. \& Clayton, R. N. Oxygen isotopic fractionation in the system quartz-albite-anorthite-water. Geochim. Cosmochim. Acta 43, 1131-1140 (1979)

34. Clayton, R. N., O'Neil, J. R. \& Mayeda, T. K. Oxygen isotope exchange between quartz and water. J. Geophys. Res. 77, 3057-3067 (1972).

35. De La Rocha, C., Brzezinski, M. A., DeNiro, M. \& Shemesh, A. Silicon-isotope composition of diatoms as an indicator of past oceanic change. Nature 395, 680 (1998).

36. Varela, D. E., Pride, C. J. \& Brzezinski, M. A. Biological fractionation of silicon isotopes in Southern Ocean surface waters. Global Biogeochem. Cy. 18, 5663-5676 (2004)

37. Leclerc, A. J. \& Labeyrie, L. Temperature dependence of the oxygen isotopic fractionation between diatom silica and water. Earth. Planet. Sci. Lett. 84, 69-74 (1987).

38. Jun, L. L. New approach to surface seawater palaeotemperatures using ${ }^{18} \mathrm{O} /{ }^{16} \mathrm{O}$ ratios in silica of diatom frustules. Nature 248, 40-42 (1974).

39. Hu, F. S. \& Shemesh, A. A biogenic-silica $\delta^{18} \mathrm{O}$ record of climatic change during the last glacial-interglacial transition in southwestern Alaska. Quatern. Res. 59, 379-385 (2003).

40. Rietti-Shati, M., Shemesh, A. \& Karlen, W. A 3000-year climatic record from biogenic silica oxygen isotopes in an equatorial high-altitude lake. Science $\mathbf{2 8 1}$, 980-982 (1998).

41. Barker, P. A. et al. A 14,000-year oxygen isotope record from diatom silica in two alpine lakes on Mt. Kenya. Science 292, 2307-2310 (2001).

42. Li, T., Zhu, S. H. \& Ogihara, M. Using discriminant analysis for multi-class classification: an experimental investigation. Knowl. Inf. Syst. 10, 453-472 (2006).

43. Pack, A. et al. Tracing the oxygen isotope composition of the upper Earth's atmosphere using cosmic spherules. Nat. Commun. 8, 15702 (2017).

44. Mueller, N. C. \& Nowack, B. Exposure modeling of engineered nanoparticles in the environment. Environ. Sci. Technol. 42, 4447-4453 (2008).

45. Gottschalk, F., Sonderer, T., Scholz, R. W. \& Nowack, B. Modeled environmental concentrations of engineered nanomaterials $\left(\mathrm{TiO}_{2}, \mathrm{ZnO}, \mathrm{Ag}\right.$ CNT, Fullerenes) for different regions. Environ. Sci. Technol. 43, 9216-9222 (2009).

46. Lu, D. W. et al. Recent advances in the analysis of non-traditional stable isotopes by multi-collector inductively coupled plasma mass spectrometry. J. Anal. At. Spectrom. 32, 1848-1861 (2017).

47. Georg, R. B., Reynolds, B. C., Frank, M. \& Halliday, A. N. New sample preparation techniques for the determination of $\mathrm{Si}$ isotopic compositions using MC-ICPMS. Chem. Geol. 235, 95-104 (2006).

48. Zambardi, T. \& Poitrasson, F. Precise determination of silicon isotopes in silicate rock reference materials by MC-ICP-MS. Geostand. Geoanal. Res. 35 , 89-99 (2011)

49. Yang, L., Zhou, L., Hu, Z. C. \& Gao, S. Direct determination of Si isotope ratios in natural waters and commercial Si standards by ion exclusion chromatography multicollector inductively coupled plasma mass spectrometry. Anal. Chem. 86, 9301-9308 (2014).

50. Clayton, R. N. \& Mayeda, T. K. The use of bromine pentafluoride in the extraction of oxygen from oxides and silicates for isotopic analysis. Geochim. Cosmochim. Acta 27, 43-52 (1963).

51. Pedregosa, F. et al. Scikit-learn: Machine Learning in Python. J. Mach. Learn. Res. 12, 2825-2830 (2011). 


\section{Acknowledgements}

This work was financially supported by the National Natural Science Foundation of China $(21825403,91843301,91543104,91743204)$, the Chinese Academy of Sciences (XDB14010400, QYZDB-SSW-DQC018), and the National Basic Research Program of China (2015CB931903, 2015CB932003). Q. L. acknowledges the China National Special Support Program for Young Top-Notch Talents.

\section{Author contributions}

Q. L. designed the research; G. J. supervised the project; X. Y. performed most of experiments; X. L. and A. Z. built the machine learning model for source identification; D. L. helped with the isotopic analysis; G. L. helped with the XRD measurements; Q. Z. gave comments on the paper; Q. L. and X. Y. analyzed the data; Q. L., X. Y., and A. Z. wrote the paper.

\section{Additional information}

Supplementary Information accompanies this paper at https://doi.org/10.1038/s41467019-09629-5.

Competing interests: The authors declare no competing interests.

Reprints and permission information is available online at http://npg.nature.com/ reprintsandpermissions/
Journal Peer Review Information: Nature Communications thanks Frank Vanhaecke, and the other anonymous reviewers for their contribution to the peer review of this work Peer reviewer reports are available

Publisher's note: Springer Nature remains neutral with regard to jurisdictional claims in published maps and institutional affiliations.

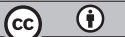

Open Access This article is licensed under a Creative Commons Attribution 4.0 International License, which permits use, sharing, adaptation, distribution and reproduction in any medium or format, as long as you give appropriate credit to the original author(s) and the source, provide a link to the Creative Commons license, and indicate if changes were made. The images or other third party material in this article are included in the article's Creative Commons license, unless indicated otherwise in a credit line to the material. If material is not included in the article's Creative Commons license and your intended use is not permitted by statutory regulation or exceeds the permitted use, you will need to obtain permission directly from the copyright holder. To view a copy of this license, visit http://creativecommons.org/ licenses/by/4.0/.

(c) The Author(s) 2019 